\author{
А. В. ВОРОБЕЙ, А. М. МАХМУДОВ, Ю. Н. ОРЛОВСКИЙ
}

Белорусская медицинская академия последипломного образования

\title{
Современные показания к операции низведения в колоректальной хирургии
}

\begin{abstract}
В статье изложен исторический анализ брюшно-анальных резекций прямой кишки с низведением сигмовидной кишки за анус и определение современных показаний к технологии низведения в хирургии толстой кишки.

Известны два варианта операций низведения: эверсионная техника и низведение с трансанальной колостомой. В ХХ веке они были альтернативой транссакральным резекциям и экстирпации прямой кишки. Это расширило возможности колоректальной хирургии. Сегодня они представляют только исторический интерес.

В XXI веке операцией выбора является низкая передняя резекция прямой кишки с колоанальным анастомозом “конец в конец” (мезоректумэктомия). Технология низведения показана при несостоятельности анальной культи, осложненной пресакральным затеком; измененной анатомии таза после первичной операции на толстой кишке; рубцевании анальной культи, анальновагинальном свище.
\end{abstract}

Ключевые слова: низведение; колоанальный анастомоз; трансанальная стома; мезоректумэктомия.

Хирургия рака прямой кишки прошла длительный и сложный путь. Teodor Kocher первым в 1875 году выполнил резекцию прямой кишки с опухолью транссакральным (транскокцигеальным) доступом [1]. Однако эта операция ассоциируется с именем P. Kraske, так как он подробно изоложил её технические детали на XIV Конгрессе Германской ассоциации хирургов в 1884 году [2]. После резекции прямой кишки он формировал в нижнем углу сакрального доступа концевую (сакральную) колостому. Для облегчения доступа к прямой кишке он предложил удалять копчик, а в более трудных ситуациях - удалять пилой Джигли два дистальных крестцовых позвонка. В 1932 году G. Turner предложил после резекции прямой кишки по P. Kraske формировать сигморектальный анастомоз “конец в конец” и выполнил 17 таких операций [3]. Однако эта операция технически выполнима при локализации нижнего края опухоли не ниже 8-10 см от ануса. Она сопровождалась высоким уровнем нагноений сакральной раны, несостоятельности швов и местных рецидивов рака. По мнению Марвина Кормана (1989), эта операция может быть показана только при доброкачественной патологии: ворсинчатых стелющихся аденомах, доброкачественных стриктурах прямой кишки, высоких ректовагинальных и ректоуретропростатических свищах [4].

В 1892 году J. Murphy предложил формировать безшовные соустья между органами пищеварительного тракта изобретенной им пуговкой [5]. Однако она существенно не улучшила качество колоректальных соустий.

В 1892 г. M. Quenu предложил, a W.Miles (1907) усовершенствовал операцию брюшно-про- межностной экстирпации прямой кишки [6,7]. Это позволило улучшить отдаленные результаты при раке, однако у пациентов имелась пожизненная концевая сигмостома.

Альтернативой таким операциям с сакральной или абдоминальной колостомой стало предложение H.Maunsell от 1892 года, поддержанное в 1901 году R.Weir [8, 9]. Они впервые выполнили резекцию опухоли прямой кишки абдоминальноанальным доступом с помощью “эверсионной” техники низведения ободочной кишки за анус. Для этого ректальную культю длиной не менее 6 см выворачивали нитями за пределы ануса, через нее низводили наружу проксимальный сегмент ободочной кишки и однорядным непрерывным швом формировали колоректальный анастомоз “конец в конец”. Затем последний “возвращали” в полость таза.

Другую технику низведения после резекции более низких опухолей прямой кишки предложили W. Babcock (1939), H. Bacon (1945) и B.Black (1955). Это были праобразы нынешних сфинктеросохраняющих операций. Операцию также выполняли двумя бригадами хирургов: со стороны брюшной полости и промежности. После мобилизации прямую кишку трансанально пересекали на уровне зубчатой линии, а сигмовидную кишку после удаления опухоли низводили за анус и фиксировали узловыми швами к перианальной коже. В течение 10-14 дней происходило сращение краев анальной культи с серозой низведенной сигмы. Избыток последней отсекали и узловыми чрезслизистыми швами окончательно формировали сигмоанальный анастомоз $[10,11,12]$. Для предотвращения некроза низведенной ободочной 
кишки W. Babcock и H. Bacon производили глубокую заднюю сфинктеротомию. Н. Васоп предложил для укрепления будущего соустья выполнять демукозацию аноректальной культи. Babcock назвал данную операцию “одноэтапной брюшнопромежностной проктосигмоидэктомией с промежностной колостомой”.

Cutait R. и Figliolini F., а независимо от них R. Turnbull - младший и A. Cuthbertson в 1961 году предложили двухэтапную технику низведения с промежностной колостомой (отсроченный анастомоз) $[13,14]$. Они низводили за эвертированную ректальную культю проксимальную ободочную кишку с избытком. Между ними накладывали однорядные узловые серозно-мышечные швы. Через 10-12 дней избыток низведенной кишки отсекали по линии соустья, накладывали узловые швы на слизистые сигмовидной и культи прямой кишок и вворачивали сигморектальное соустье в полость малого таза.

Несмотря на прогрессивную для того времени идею первичного восстановления кишечной непрерывности после резекции толстой кишки, операции низведения имели ряд серьезных недостатков.

Так, J. Waugh и J. Turner в 1958 году сообщили, что после низкой резекции прямой кишки с низведением по Васоп только у 10 \% пациентов была нормальная анальная континенция [15]. Основной проблемой являлся некроз и ретракция в полость малого таза низведенной за анус ободочной кишки, достигавшие $22 \%$. В результате послеоперационная летальность колебалась в пределах 1-10 \%, а несостоятельность швов с образованием тазовых абсцессов наблюдалась в 10 30 \%. Нарушения континенции наблюдали у 75 \% пациентов [16]. После операции Васоn функция анального жома была достаточной, но 83 \% пациентов могли оправиться только после клизмы [17].

Все вышеперечисленные операции для лечения колоректального рака представляют сегодня только исторический интерес. Уже более 40 лет наилучшие ранние послеоперационные и отдаленные онкологические результаты во всем мире дает мезоректумэктомия по R. Heald [18]. Низкая передняя резекция прямой кишки при любой патологии дает наибольший эффект при формировании колоанальных соустий двойной степлерной техникой как при открытой, так и лапароскопической хирургии [19].

В конце XIX века операции низведения значительно расширили возможности хирургического лечения рака прямой кишки. Они стали альтернативой транссакральным доступам [1, 2], кон- цевой пожизненной колостоме после плановой экстирпации прямой кишки $[6,7]$; концевой колостоме после обструктивной резекции толстой кишки по Гартману [20]. Операции низведения в вариантах эверсионной техники и промежностной колостомы были первыми способами первичных колоректальных и колоанальных анастомозов, сформировали новый подход к профилактике несостоятельности швов низких анастомозов в колоректальной хирургии [16]. Идея сохранения анального жома при низких опухолях прямой кишки явилась предпосылкой современных сфинктеросохраняющих и супернизких интерсфинктерных резекций прямой кишки [15]. Двухбригадный способ оперирования рака прямой кишки (“abdominoanal excision”) был предшественником современной мезоректумэктомии из открытого абдоминального или лапароскопического доступов [18].

Однако классические операции низведения сыграли свою историческую роль и навсегда ушли в прошлое. Хорошая более 100 лет назад идея сфинктеросохраняющих операций с первичным колоректальным или колоанальным анастомозом без необходимости проксимальной превентивной петлевой стомы давала большой процент плохих результатов $[15,17]$. Сегодня нет альтернатив мезоректумэктомии при любой патологии прямой кишки. Основной проблемой низведения ободочной кишки за анус после резекции прямой кишки была ишемия низводимой кишки. Её причинами являются: немагистральный тип ветвления нижней брыжеечной артерии, тучная брыжейка ободочной кишки, сдавление низведенной ободочной кишки анальным жомом. Вследствие этого развивался некроз низведенной кишки при её декомпенсированной ишемии или ретракция кишки в малый таз при суб- и компенсированной ишемии с последующим пресакральным затеком, перитонитом или рубцовой стриктурой колоанального соустья [15]. Сфинктеротомия как способ профилактики сдавливания низведенной кишки часто приводила к анальному недержанию после операции [17].

Попытки низведения ободочной кишки за анус в XXI веке, по нашему мнению, могут быть объяснены, но не оправданы, только следующими причинами: 1) псевдостраховка хирурга от неблагоприятного исхода операции, когда он не уверен в жизнеспособности дистального конца низводимого к анальной культе края ободочной кишки и не владеет приемами колопластики; 2) хирург не умеет выполняет трансанально первичный колоанальный анастомоз “конец в конец” однорядным ручным швом или степле- 
ром; 3) отсутствует опыт мезоректумэктомии (открытой или лапароскопической); 4) в стационаре нет линейных и циркулярных степлеров.

Для успешного формирования соустий с анальным каналом необходимо знание способов удлинения брыжеек ободочной и тонкой кишок [21, 22]. Наиболее сложным, но и наиболее эффективным из них является траспозиция брыжеечных сосудов в соответствующие подвздошные сосуды [22]. При неэффективности всех известных приемов энтеро- и колопластики после обструктивной резекции ободочной кишки можно резецировать сигмовидную и поперечно-ободочную кишку и сформировать антиперистальтический цекоанальный анастомоз по методике A. Sarli [23].

По опыту нашей клиники идею низведения ободочной или тонкой кишки через анальную культю за анус можно использовать в XXI веке в некоторых сложных ситуациях после первичных операций на толстой кишке. Это: 1) несостоятельность анальной культи с образованием тазового внутреннего свища или пресакральном затеке с воспалительными грануляциями; 2) грубое рубцевание купола анальной культи, когда формирование ручного или степлерного колоанального соустья “конец в конец” невыполнимо;

\section{СПИСОК ЛИТЕРАТУРЫ}

1. Kocher T. The colon, rectum and anus / Quoted in Rankin F. W., Bargen J. A., Burie L. A. (eds). Philadelphia: WB Saunders; 1875.

2. Kraske P. Ueber die Entstehungsekundarer Krebsgeschwüredurch Impfung / P. Kraske // Zentralbl. Chir. - 1884. - Vol. 11. - P. 801.

3. Turner G. G. Conservative resection of the rectum by the lower route: The after results in seventeen cases / G. G. Turner // Acta. Chir. Scand. - 1932. - Vol. 72. - P. 519-535.

4. Corman M. L. Colon and rectal surgery / M. L. Corman. B. Lippincott Company, Philadelphia; Corman. - 1051 p.

5. Murphy J. B. Cholecysto-intestinal, gastro-intestinal, enterointestinal anastomosis, and approximation without sutures / J. B. Murphy // Med. Record. - 1892. - Vol. 42. - P. 665-676.

6. Queny M Technique operative pour L'amputation du rectum cancereux / M. Queny // Bull Soc. Chirurgie. - 1987. - Vol. 23. - P. 163.

7. A method of performing abdomino-perineal excision for carcinoma of the rectum and the terminal portion of the pelvic colon / W. E. Miles // Lancet. - 1908. - Vol. 2. - P. 1812-1813.

8. Maunsell H. W. A new method of excising the two apper portion of the rectum and the lower segment of the sigmoid flexure of the colon / H. W. Maunsell // Lancet. - 1892. - Vol. 2. - P. 473-476.

9. Weir R. F. An improved method of treating high-seated cancers of the rectum / R. F. Weir // JAMA. - 1901. - Vol. 37. P. 801-803.

10. Babcock W. W. Experiences with resection of the colon and the elimination of colostomy / W. W. Babcock // Am. J. Surg. 1939. - Vol. 4. - P. 186-203.
3) измененная анатомия таза после первичной операции на толстой кишке, когда нет уверенности в достаточной площадке в малом тазу между крестцом и мочевым пузырём или сводом влагалища для наложения степлерного соустья; 4) каллезный анально-вагинальный свищ; 5) формирование после колпроктэктомии S-образного тонкокишечного резервуара с трасанальной илеостомой как вариант одноэтапной восстановительной колпроктэктомии. Во всех вышеперечисленных ситуациях показано формирование проксимальной превентивной илеостомы.

Операции низведения (эверсионный вариант и с трансанальной колостомой) были важными и прогрессивными этапами развития колоректальной хирургии до эпохи мезоректумэктомии и степлеров.

Сегодня показанием к низведению с трансанальной коло- или илеостомой являются “трудная” анальная культя или ее культе-вагинальный свищ у пациентов с концевыми коло- или илеостомами.

Владение всеми приемами интенстинопластики, включая ангиотранспозицию, позволяет сформировать анастомоз с анальной культей без необходимости низведения кишки за анус.
11. Bacon H. E. (1945). Evolution of sphincter muscle preservation and reestablishment of continuity in the operative treatment of rectal and sigmoid cancer / H. E. Bacon // Surg. Gynecol. Obstet., 81, 113-127.

12. Black B. M. Recurrent carcinoma of the rectum and rectosigmoid: Results of treatment after continence preserving procedures / B. M. Black, A. H. Kelly // Arch. Surg. - 1955. Vol. 72. - P. 538-542.

13. Cutait D. E. A new method of colorectal anastomosis in abdominoperineal resection / D. E. Cutait, F. J. Figliolini // Dis. Colon Rectum. - 1961. - Vol. 4. - P. 335-342.

14. Turnbull R. B. Jr. Abdominorectal pull-through resection for cancer and for Hirschsprung's disease: Delayed posterior colorectal anastomosis / R. B. Jr. Turnbull, A. Cuthbertson // Cleve Clin. Q. - 1961. - Vol. 28. - P. 109-115.

15. Waugh J. M. A study of 268 patients with carcinoma of the midrectum treated by abdominoperineal resection with sphincter preservation / J. M. Waugh, J. C. Turner // Surg. Gynec. Obstet. 1958. - Vol. 107. - P. 777-781.

16. Bennett R. C. The place of pull-through operations in the treatment of carcinoma of the rectum / R. C. Bennett // Dis. Colon Rectum. - 1976. - Vol. 19. - P. 420-424.

17. Rosen L. Clinical and manometric evaluation of continence after the Bacon two-stage pull-through procedure / L. Rosen, I. T. Khubchandani, J. A. Sheets // Dis. Colon Rectum. - 1985. Vol. 28. - P. 232-234.

18. Heald R. J. Recurrence and survival after total mesorectal excision for rectal cancer / R. J. Heald, R. D. Ryall // Lancet. 1986. - Vol. 1. - P. 1479-1482.

19. Cohen Z. Double stapling technique for low anterior resection 
/ Z. Cohen, E. Myers, B. Langer // Dis. Colon Rectum. - 1983. Vol. 26. - P. 231-235.

20. Hartmann H. Nouveau proceded'ablation des cancers de la partieterminale du colon pelvien. TrentiemeCongres de Chirurgie / H. Hartmann. - Strasbourg, France. - 1921. - P. 411-414.

21. Воробей А. В. Реабилитация больных с энтеростомами / А. В. Воробей // Росс. журнал гастроэнтерол. Гепатол. Коло-

\section{REFERENCES}

1. Kocher, T. (1875). Quoted in Rankin, F.W., Bargen, J.A., Burie, L.A. (eds): The colon, rectum and anus. Philadelphia: WB Saunders.

2. Kraske, P (1884). Ueber die Entstehungsekundarer Krebsgeschwüredurch Impfung. Zentralbl. Chir., 11, 801.

3. Turner, G.G. (1932). Conservative resection of the rectum by the lower route: The after results in seventeen cases. Acta. Chir. Scand., 72, 519-535.

4. Corman, M.L. (1989). Colon and rectal surgery. B. Lippincott Company, Philadelphia.

5. Murphy, J.B. (1892). Cholecysto-intestinal, gastro-intestinal, entero-intestinal anastomosis, and approximation without sutures. Med. Record., 42, 665-676.

6. Queny, M. (1897). Technique operative pour L'amputation du rectum cancereux. Bull Soc. Chirurgie, Paris.

7. Miles, W.E. (1908). A method of performing abdominoperineal excision for carcinoma of the rectum and the terminal portion of the pelvic colon. Lancet, 2, 1812-1813.

8. Maunsell, H.W. (1892). A new method of excising the two apper portion of the rectum and the lower segment of the sigmoid flexure of the colon. Lancet, 2, 473-476.

9. Weir, R.F. (1901). An improved method of treating highseated cancers of the rectum. JAMA, 37, 801-803.

10. Babcock, W.W. (1939). Experiences with resection of the colon and the elimination of colostomy. Am. J. Surg., 4, 186-203. 11. Bacon, H.E. (1945). Evolution of sphincter muscle preservation and reestablishment of continuity in the operative treatment of rectal and sigmoid cancer. Surg. Gunecol. Obstet., 81, 113-127.

12. Black, B.M., \& Kelly, A.H. (1955). Recurrent carcinoma of the rectum and rectosigmoid: Results of treatment after continence preserving procedures. Arch. Surg., 72, 538-542.

13. Cutait, D.E., \& Figliolini, F.J. (1961). A new method of colorectal anastomosis in abdominoperineal resection. Dis. проктол. - № 8 (3). - С. 68-75.

22. Воробей А. В. Реабилитация стомированных больных / А. В. Воробей, И. Н. Гришин. - Минск : Беларускаянавука, 2003. - 190 c.

23. Sarli A. Subtotal colectomy with antiperistalticcecorectal anastomosis / A. Sarli // Tech. Coloproctol. - 2002. - Vol. 6 (1). - P. 23-26.

Colon. Rectum, 4, 335-342.

14. Turnbull, R. B. Jr., \& Cuthbertson, A. (1961). Abdominorectal pull-through resection for cancer and for Hirschsprung's disease: Delayed posterior colorectal anastomosis. Cleve Clin. Q., 28, 109115.

15. Waugh, J.M., \& Turner, J.C. (1958). A study of 268 patients with carcinoma of the midrectum treated by abdominoperineal resection with sphincter preservation. Surg. Gynec. Obstet., 107, 777-781.

16. Bennett, R.C. (1976). The place of pull-through operations in the treatment of carcinoma of the rectum. Dis. Colon. Rectum, 19, 420-424.

17. Rosen, L., Khubchandani, I.T., \& Sheets, J.A. (1985). Clinical and manometric evaluation of continence after the Bacon twostage pull-through procedure. Dis. Colon Rectum, 28, 232-234.

18. Heald, R.J., \& Ryall, R.D. (1986). Recurrence and survival after total mesorectal excision for rectal cancer. Lancet, 1, 14791482.

19. Cohen, Z., Myers, E., \& Langer, B. (1983). Double stapling technique for low anterior resection. Dis. Colon Rectum, 26, 231235.

20. Hartmann, H. (1921). Nouveau proceded'ablation des cancers de la partieterminale du colon pelvien. Trentieme Congres de Chirurgie. Strasbourg, France.

21. Varabey, A.V. (1998). Reabilitatsiya bolnykh s enterostomami [Rehabilitation of patients with enterostomas]. Ros. Zhurnal gastroenterol, gepatol, koloproktol - Russian Journal of Gastroenterology, Gepatology, Coloproctology, 8 (3), 68-75 [in Russian].

22. Varabey A.V., \& Grishin, I.N. (2003). Reabilitatsiya stomirovannykh bolnykh [Rehabilitation of ostomy patients]. Minsk: Belaruskaya navuka [in Russian].

23. Sarli, A (2002). Subtotal colectomy with antiperistalticcecorectal anastomosis. Tech. Coloproctol., 6 (1), 23-26.

\section{A. V. VARABEI, A. M. MAKHMUDOV, Y. N. ARLOUSKI}

Belarusian Medical Academy of Postgraduate Education

\section{MODERN INDICATIONS FOR PULL-THROUGH PROCEDURE IN COLORECTAL SURGERY}

The article adduces the literature review of abdomino-anal resection of the rectum by pull-through and modern indication for pullthrough technique in colorectal surgery.

There are two variants of pull-through procedures: abdomino-anal excision (eversion technique) and abdominoperianal proctosigmoidoectomy with perianal colostomy. They were alternative methods for transsacral rectal resection and Quenu-Miles procedure in 20 century and have only historical interest now.

Low anterior resection with coloanal anastomosis "end to end" (mesorectumectomy) is a main surgical technique in 21 century. Pullthrough technique is used in such cases: leakage of anal stump, complicated by presacral granulations; altered pelvic anatomy after primary colorectal surgery; scars of anal stump; ano-vaginal fistula.

Key words: pull-through technique; coloanal anastomosis; perianal colostomy; mesorectumectomy. 


\title{
ОГЛЯДИ
}

\author{
О. В. ВОРОБЕЙ, А. М. МАХМУДОВ, Ю. М. ОРЛОВСЬКИЙ
}

Білоруська медична академія післядипломної освіти, Мінськ

\section{СУЧАСНІ ПОКАЗАННЯ ДО ОПЕРАЦЇ̈ НИЗВЕДЕННЯ В КОЛОРЕКТАЛЬНИЙ ХІРУРГЇ}

У статті викладено історичний аналіз черевно-анальних резекцій прямої кишки з низведенням сигмоподібної кишки за анус і визначення сучасних показань до технології низведення в хірургії товстої кишки.

Відомі два варіанти операцій низведення: еверсійна техніка та низведення з трансанальною колостомою. У XX столітті такі операції були альтернативою транссакральним резекціям та екстирпації прямої кишки. Це розширило можливості колоректальної хірургії, а сьогодні вони становлять тільки історичний інтерес.

У XXI столітті операцією вибору є низька передня резекція прямої кишки з колоанальним анастомозом “кінець в кінець” (мезоректумектомія). Технологія низведення показана при неспроможності анальної кукси, що ускладнена пресакральним затіканням; зміненій анатомії таза після первинної операції на товстій кишці; рубцюванні анальної кукси, анально-вагінальній нориці.

Ключові слова: низведення; колоанальний анастомоз; трансанальна стома; мезоректумектомія. 